\title{
Classifying Different Types of Double Triggering Based on Airway Pressure and Flow Deflection in Mechanically Ventilated Patients
}

\author{
Kuang-Ming Liao MD MSc, Chih-Ying Ou MD, and Chang-Wen Chen MD MSc
}

\begin{abstract}
BACKGROUND: Double-triggering (DT) is a frequent type of patient-ventilator asynchrony and has potentially severe consequences, such as alveolar overdistention or the generation of intrinsic PEEP. However, the first breath of DT could be patient-triggered (DT-P), auto-triggered (DT-A), or ventilator-triggered (DT-V). OBJECTIVE: To differentiate DT-P, DT-A, and DT-V using airway pressure or flow changes during the trigger-delay phase in ventilated patients. METHODS: Fourteen mechanically ventilated patients with DT were included. All patients were on flow-triggered ventilation modes and received either continuous mandatory ventilation or pressure support ventilation. Breaths in which the first breath was associated with an esophageal pressure drop of $>1 \mathrm{~cm} \mathrm{H} \mathrm{H}_{2} \mathrm{O}$ were categorized as DT-P. Breaths in which the first breath occurred at the ventilator set cycle were categorized as DT-V. Breaths in which the first breath occurred earlier than the ventilator set cycle without esophageal pressure drop were categorized as DT-A. The pressure drop and flow change at $0.13 \mathrm{~s}\left(\mathrm{PD}_{\mathbf{0 . 1 3}}\right.$ and $\mathrm{F}_{0.13}$, respectively) in the trigger-delay phase were calculated from the nadir. RESULTS: There were 507 double-triggered breaths: 271 DT-V (53\%), 50 DT-A $(10 \%)$, and 186 DT-P $(37 \%)$. The PD P.13 $_{0}$ for DT-V, DT-A, and DT-P were $0.16 \pm 0.12 \mathrm{~cm} \mathrm{H}_{2} \mathrm{O}$, $0.25 \pm 0.17 \mathrm{~cm} \mathrm{H}_{2} \mathrm{O}$, and $1.34 \pm 0.67 \mathrm{~cm} \mathrm{H}_{2} \mathrm{O}$, respectively. The $\mathrm{F}_{0.13}$ for DT-V, DT-A, and DT-P were $2.11 \pm 2.31 \mathrm{~L} / \mathrm{min}, 2.64 \pm 2.07 \mathrm{~L} / \mathrm{min}$, and $16.51 \pm 8.02 \mathrm{~L} / \mathrm{min}$, respectively. The best discriminatory criteria for differentiating DT-P from DT-V and DT-A, based on the Youden index (sensitivity + specificity - 1) was $\mathrm{PD}_{0.13} \geq 0.49 \mathrm{~cm} \mathrm{H}_{2} \mathrm{O}$, which had a Youden index of $95 \%$. CONCLUSION: DT-P can be distinguished from DT-V and DT-A by using airway pressure deflections in the trigger-delay phase. Key words: patient-ventilator asynchrony; double triggering. [Respir Care 2011;56(4):460-466. (C) 2011 Daedalus Enterprises]
\end{abstract}

\section{Introduction}

Patient-ventilator asynchrony is a frequently observed phenomenon in ventilated patients. According to a recent

Kuang-Ming Liao MD MSc is affiliated with the Chiali Hospital, Chiali Town, Tainan, Taiwan. Chih-Ying Ou MD is affiliated with the Division of Chest Medicine; and Chang-Wen Chen MD MSc is affiliated with the Medical Intensive Care Unit, Department of Internal Medicine, National Cheng Kung University Hospital, Tainan, Taiwan.

Chang-Wen Chen MD MSc presented a version of this paper at the 22nd Annual Congress of the European Society of Intensive Care Medicine, held October 11-14, 2009, in Vienna, Austria.

This study was partly supported by grants from the National Science Council of Taiwan (98-2320-B-006-002-MY2, NCKUH-9704017 and NCKUH-9804001.

The authors have disclosed no conflicts of interest. study, ${ }^{1}$ at least $50 \%$ of patients who receive mechanical ventilation for more than 24 hours display some conflict with the ventilator. Aside from an ineffective triggering, double-triggering (DT) is another major type of patientventilator asynchrony. ${ }^{1}$ DT is usually defined as 2 ventilator insufflations delivered within one patient inspiratory effort, and the first trigger should be patient-triggered (DTP), ${ }^{1-4}$ but can be ventilator-triggered (DT-V) or auto-triggered (DT-A). ${ }^{5}$ DT-P is likely to occur in patients with short inspiratory times, lower $\mathrm{P}_{\mathrm{O}_{2}} / \mathrm{F}_{\mathrm{IO}_{2}}$, high maximum

\footnotetext{
Correspondence: Chang-Wen Chen MD MSc, Medical Intensive Care Unit, Department of Internal Medicine, National Cheng Kung University Hospital, 138 Sheng-Li Road, Tainan 704, Taiwan. E-mail: cwchen@mail.ncku.edu.tw.
}

DOI: $10.4187 /$ respcare.00731 
inspiratory pressure, high PEEP, and greater expiratory trigger settings. ${ }^{1,4}$ In our opinion, a direct prolongation of inspiration time in a continuous mandatory ventilation mode or a change of expiratory trigger setting or pressurization rate in pressure-support ventilation is a reasonable strategy for abolishing DT-P. ${ }^{4}$ DT-V is usually due to disharmony between the patient's breath rate and the set ventilator rate. Prolonging the inspiratory time may not be helpful. An adjustment of trigger sensitivity may be needed for DT-A. DT is likely to be associated with high tidal volume, which may create intrinsic PEEP in patients with expiratory flow limitation, and increase the work of breathing. In patients with acute lung injury, high tidal volume may cause alveolar overdistention and exacerbate lung injury. DT may also disrupt sleep. ${ }^{6}$

Distinguishing DT-V, DT-P, and DT-A can be done only by examining the inspiratory effort on the tracing of the esophageal pressure, transdiaphragmatic pressure, or diaphragmatic electromyogram. Unfortunately, these invasive procedures are usually not available in clinical practice. Differentiating DT-P from DT-V or DT-A based on airway pressure and flow tracings may be problematic with a flow-triggered ventilation mode. ${ }^{4} \mathrm{~A}$ subjective criterion of abrupt airway pressure drop of $>0.5 \mathrm{~cm} \mathrm{H}_{2} \mathrm{O}$ before a ventilator-assisted breath is prone to be inaccurate because the onset of inspiratory effort is hard to determine. ${ }^{1}$ Although a triggered breath can easily be identified with a modern ventilator, auto-triggering may also be hard to identify. In view of the different pathophysiological bases between these types of DT, we sought to establish objective criteria for differentiating DT-V, DT-P, and DT-A, based on 2 variables universally available on current ventilators: airway pressure and flow. As DT-P implies obvious inspiratory drive, ${ }^{1}$ we hypothesized that airway pressure and flow changes in the trigger-delay phase should be significantly different between the first breath of DT-P and that of DT-V or DT-A. In addition to establishing an objective criteria, we also studied the effect of changes of ventilator settings on DT-P and DT-V, to test our hypothesis. We used esophageal pressure deflection as an objective measure of inspiratory effort.

\section{Methods}

This study was performed at National Cheng Kung University Hospital, Taiwan, and approved by the hospital's ethics committee. All subjects or their next of kin gave written informed consent.

\section{Subjects}

Between March 2006 and September 2008, all mechanically ventilated patients in our 10-bed respiratory intensive care unit were screened daily for the appearance of patient-ventilator asynchrony. The inclusion criteria were: hemodynamically stable; no inotropic agents; ventilated with an $\mathrm{F}_{\mathrm{IO}_{2}}$ of $<0.5$ and PEEP $\leq 10 \mathrm{~cm} \mathrm{H} \mathrm{H}_{2} \mathrm{O}$, and agreement on the placement of an esophageal balloon. The exclusion criteria were pregnancy, unstable angina, myocardial infarction or aortic dissection as a cause of admission, and nasal or oropharyngeal lesions that prohibited the placement of an esophageal balloon. A total of 762 patients were ventilated during the study period, and we included 68 patients. Ventilators used included PuritanBennett 840 (Tyco International, Princeton, New Jersey), Galileo (Hamilton Medical, Bonaduz, Switzerland), and Servo-i (Maquet, Solna, Sweden). To validate our hypothesis for management of DT-P and DT-V we studied an additional 12 patients with DT-P or DT-V, before and after changes of ventilator settings. In those 12 patients we did not place an esophageal balloon.

In 68 patients we placed an esophageal balloon in the lower third of the esophagus, which we inflated with $0.5 \mathrm{~mL}$ of air. Proper balloon placement was verified with the occlusion test. ${ }^{7}$ Air flow was measured using a pneumotachograph (PN 155362, Hamilton Medical, Bonaduz, Switzerland), connected to a differential pressure transducer (MP 45, Validyne, Northridge, California). The flow sensor was placed between the endotracheal tube and the Y-piece. Tidal volume was calculated by integrating the flow signal. Airway and esophageal pressure were measured individually, with 2 differential pressure transducers (P300D, Validyne, Northridge, California). All signals were sampled and digitalized at $100 \mathrm{~Hz}$, and data were stored in data-acquisition software (AcqKnowledge, Biopac, Goleta, California). All patients were studied in a semi-erect position if possible. If clinically required, endotracheal suctioning was performed before the measurement. The initial ventilator settings were selected by the attending physician and respiratory therapist. The ventilator triggering type could be changed to flow-triggering during the recording period if the initial setting was pressure-triggered. We recorded the pressure and flow data for an average of 10 20 min with each patient. If deemed necessary, adjustment of the ventilator settings was allowed during the recording period. Breaths with a questionable esophageal pressure signal were not included for further analysis.

\section{Definitions of DT-P, DT-V, and DT-A}

DT was defined as 2 consecutive triggers separated by an expiratory time $<50 \%$ of the mean inspiratory time. If the first trigger had an esophageal pressure drop of $>1 \mathrm{~cm} \mathrm{H}_{2} \mathrm{O}$, the breath was categorized as DT-P. ${ }^{8}$ Breaths in which the first breath occurred at the ventilator set time trigger, without concomitant esophageal pressure drop, were categorized as DT-V. Breaths in which the first trigger occurred earlier than the ventilator set time trigger, 

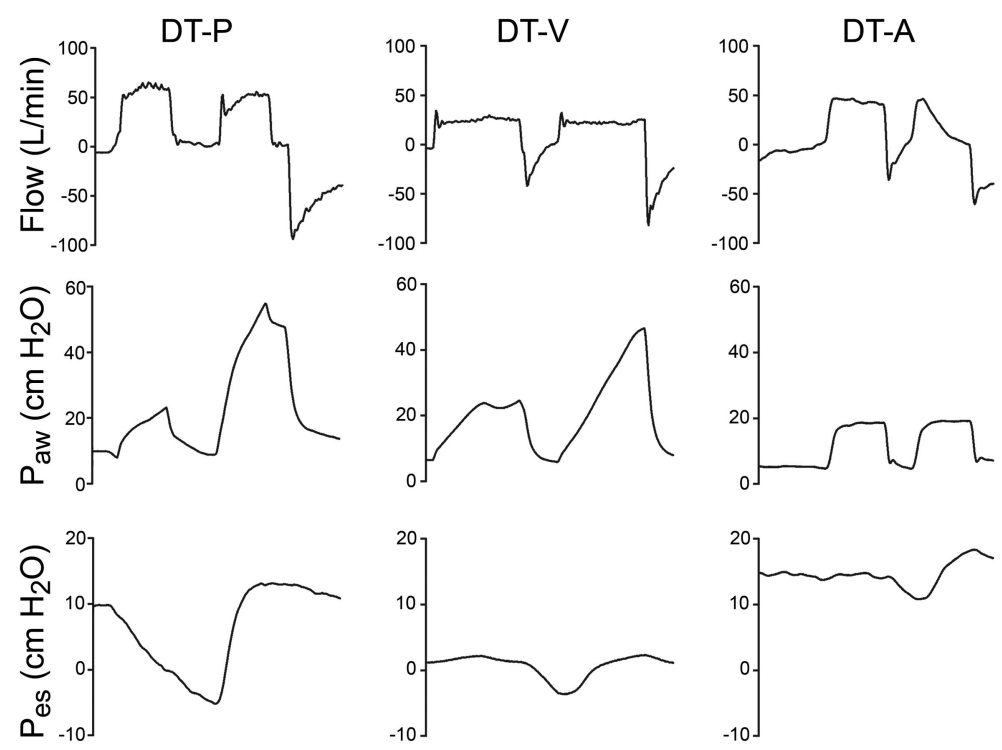

Fig. 1. Typical flow, airway pressure, and esophageal pressure tracings of double-triggering, by the patient (DT-P), the ventilator (DT-V), and auto-triggering (DT-A).

without concomitant esophageal pressure drop, were categorized as DT-A (Fig. 1). The first trigger of the DT breath was used for further analysis.

\section{Estimation of the Inspiratory Swing in the Inspiratory Trigger-Delay Phase From Airway Pressure and Flow Tracings}

Bench studies of modern ventilators showed that trigger delay may vary with inspiratory flow rate, the type of ventilator, and respiratory mechanics. ${ }^{9-11}$ It may be difficult to determine the onset of inspiratory effort from airway pressure and flow tracings, so any arbitrary definition of an inspiratory effort from airway flow and pressure tracing is subject to criticism. However, in bedside ventilator simulation of inspiratory efforts, ${ }^{9}$ we found an inspiratory-trigger-delay range of $0.07-0.13 \mathrm{~s}$, when both inspiratory effort and ventilator type (PB840, Servo, or Galileo) were taken into consideration. The upper limit was $0.1 \mathrm{~s}$ with lower effort, and $0.13 \mathrm{~s}$ with higher effort. ${ }^{9}$ We thus selected $0.13 \mathrm{~s}$ from airway pressure and flow tracings for estimating the inspiratory trigger delay in our patients, because we believe that DT-P is associated with stronger inspiratory effort. We calculated the pressure drop at $0.13 \mathrm{~s}\left(\mathrm{PD}_{0.13}\right)$ and the flow change at $0.13 \mathrm{~s}\left(\mathrm{~F}_{0.13}\right)$ during the trigger-delay phase (retrograde from the nadir of the airway pressure tracing) for DT-V, DT-P, and DT-A (Fig. 2).

\section{Statistical Analysis}

Results are given as mean $\pm \mathrm{SD}$, unless otherwise specified. We used the paired $t$ test to compare continuous
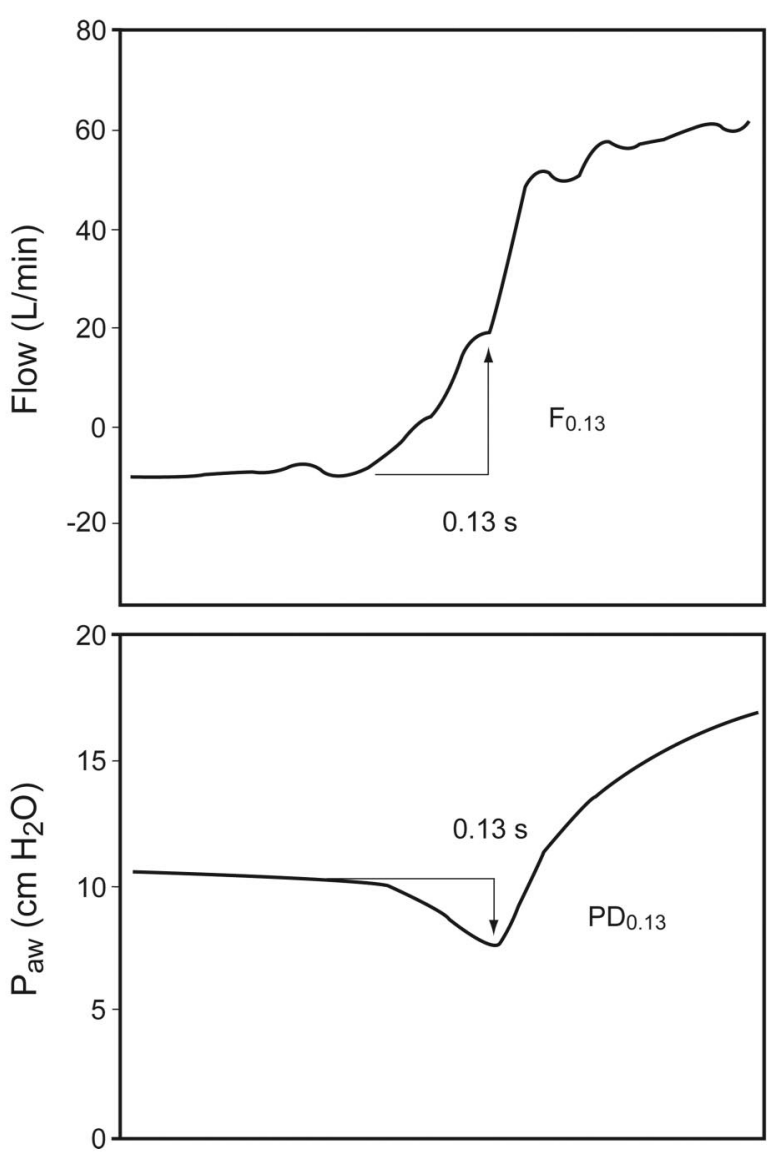

Fig. 2. Pressure drop $\left(\mathrm{PD}_{0.13}\right)$ and flow change $\left(\mathrm{F}_{0.13}\right)$ at $0.13 \mathrm{~s}$ during the trigger-delay phase. 
variables between 2 matched groups. We created scatter plots of pressure and flow changes to characterize their distributions. $P$ values $<.05$ were considered significant. We calculated airway pressure and flow changes for detecting DT-P, DT-V, and DT-A with receiver operating characteristic curves, to reveal the detection power, and the areas under the curve. We used the Youden index ${ }^{12}$ (sensitivity + specificity -1 ) to determine the optimal criteria for detecting DT-P. We used statistics software for the analysis (Prism 4, GraphPad Software, San Diego, California).

\section{Results}

We recorded data from 68 patients. Fifteen patients were excluded: 7 because they had no asynchrony; 5 because of poor esophageal pressure tracing; and 3 because of frequent hiccup. In the 53 included patients, the mean recording period was $18.6 \pm 6.8 \mathrm{~min}$. We analyzed 21,810 breaths, and 4,134 breaths showed patient-ventilator asynchrony: $3,222(78 \%)$ showed ineffective triggering in the expiratory phase; $233(6 \%)$ showed ineffective triggering in the inspiratory phase; 507 (12\%) showed various forms of DT; 135 (3\%) were auto-triggered; and a few breaths were short-cycled.

Table 1 describes the 14 subjects who demonstrated DT. All the patients were on continuous mandatory ventilation or pressure support modes with flow-triggering set at $2 \mathrm{~L} /$ min (or flow-trigger scale 2 with Servo-i), which is a common setting in our respiratory intensive care unit. We excluded recordings on pressure-triggered modes. There were a total of 507 breaths with DT-V, DT-A, or DT-P, among 14 patients: 271 DT-V, 50 DT-A, and 186 DT-P. The mean accumulated tidal volume for all the DT breaths was $773 \pm 211 \mathrm{~mL}(13.2 \pm 3.5 \mathrm{~mL} / \mathrm{kg}$ ideal body weight), the mean tidal volume for the normal breaths was $493 \pm 94 \mathrm{~mL}(8.5 \pm 1.5 \mathrm{~mL} / \mathrm{kg}$ ideal body weight $)$.

\section{Airway Pressure and Flow Changes in the Trigger- Delay Phase for Discriminating the Double- Triggering Types}

Table 2 shows the $\mathrm{PD}_{0.13}$ and $\mathrm{F}_{0.13}$ data. The $\mathrm{PD}_{0.13}$ and $\mathrm{F}_{0.13}$ of the DT-P breaths were higher than those of the DT-A and DT-V breaths. For distinguishing DT-P from DT-A and DT-V, the area under the receiver operating characteristics curve was 0.99 for $\mathrm{PD}_{0.13}$ and 0.97 for $\mathrm{F}_{0.13}$. Table 3 shows the best $\mathrm{PD}_{0.13}$ and $\mathrm{F}_{0.13}$ values for discriminating DT-P from DT-V and DT-A. PD $_{0.13} \geq 0.49$ $\mathrm{cm} \mathrm{H}_{2} \mathrm{O}$ is the best discriminator as a whole, with minimal difference among the 3 ventilator types. $\mathrm{F}_{0.13}$ was a poor discriminator with the Servo-i ventilator. The best $\mathrm{PD}_{0.13}$ and $\mathrm{F}_{0.13}$ values for differentiating DT-A from DT-V were $\mathrm{PD}_{0.13} \geq 0.28 \mathrm{~cm} \mathrm{H}_{2} \mathrm{O}$ (sensitivity $38 \%$, specificity $91 \%$ ) and $\mathrm{F}_{0.13} \geq 2.43 \mathrm{~L} / \mathrm{min}$ (sensitivity $46 \%$, specificity $76 \%$ ). It is difficult to separate DT-V from DT-A based on airway pressure and flow changes during the inspiratory trigger-delay phase.

\section{Esophageal Pressure Drop and Duration of Neural Inspiration Between the First DT-P Breath and Its Previous Normally Triggered Breath}

Data on the esophageal pressure drop between the first DT-P breath and its previous, normally triggered breath were available from 6 patients (54 breath pairs). Esophageal pressure drop was significantly greater in the first DT-P breath in 5 patients $\left(9.5 \pm 4.4 \mathrm{~cm} \mathrm{H}_{2} \mathrm{O}\right.$ in the normally triggered breath vs $11.4 \pm 4.8 \mathrm{~cm} \mathrm{H}_{2} \mathrm{O}$ in the first DT-P breath, $n=54$ ). Neural inspiratory time, calculated from the onset of rapid decline of esophageal pressure to the nadir, ${ }^{13}$ was significantly longer in the first DT-P breath than in the previous normally triggered breath in all 6 patients displaying DT-P $(0.79 \pm 0.28 \mathrm{~s}$ in the normally triggered breath vs $0.93 \pm 0.22 \mathrm{~s}$ in the first DT-P breath).

\section{Management of DT-P and DT-V}

We studied 12 patients with DT-P and DT-V but without placement of esophageal balloon before and after readjustment of ventilator settings. We examined the airway pressure and flow tracings for at least $5 \mathrm{~min}$ before and after ventilator adjustment in 6 patients with DT-P and 6 with DT-V. In the patients with DT-P, 3 patients were on pressure support ventilation, 2 were on a pressure control mode, and 1 was on a volume control mode. Their number of DT breaths averaged 7 per minute, which decreased to 0.2 per minute after prolonging the inspiratory time, by decreasing the expiratory flow cycle threshold in 3 patients on pressure support, and by increasing the inspiration time in 2 patients on pressure control ventilation. In the patient with DT-P on a volume control mode, DT was abolished by a change to a pressure support mode, with an increase in inspiratory time by appropriately adjusting the expiratory flow cycle threshold. Although not used in the present study, the inspiratory time can also be prolonged by reducing the pressurization ramp. ${ }^{4}$

All 6 patients with DT-V were on pressure-control ventilation, and the number of DT breaths averaged 6 per minute. Their initial mandatory respiratory rate averaged 17 breaths/min, and DT-V breaths were completely abolished by decreasing the mandatory respiratory rate to an average of 8 breaths/min.

\section{Discussion}

We demonstrated in this study that DT-P can be reliably separated from DT-V and DT-A based on airway pressure 


\section{Classifying Different Types of Double Triggering}

Table 1. Subjects, Ventilators, Modes, Tidal Volume, Breaths, and Double-Triggering Events*

\begin{tabular}{|c|c|c|c|c|c|c|c|c|c|c|c|c|c|}
\hline $\begin{array}{l}\text { Patient } \\
\text { No. }\end{array}$ & $\begin{array}{l}\text { Age } \\
(y)\end{array}$ & Sex & Diagnoses & $\begin{array}{l}\text { Ramsay } \\
\text { Scale } \\
\text { Score }\end{array}$ & $\begin{array}{l}\mathrm{P}_{\mathrm{aO}_{2}} / \mathrm{F}_{\mathrm{IO}_{2}} \\
(\mathrm{~mm} \mathrm{Hg})\end{array}$ & $\begin{array}{l}\text { Days of } \\
\text { Ventilation }\end{array}$ & $\begin{array}{l}\text { Ventilator } \\
\text { Model }\end{array}$ & $\begin{array}{l}\text { Ventilation } \\
\text { Mode }\end{array}$ & $\begin{array}{c}\mathrm{V}_{\mathrm{T}} \\
(\mathrm{mL} / \mathrm{kg} \\
\mathrm{IBW})\end{array}$ & $\begin{array}{c}\text { Total } \\
\text { Breaths } \\
\text { Recorded }\end{array}$ & DT-P & DT-V & DT-A \\
\hline 1 & 57 & $\mathrm{M}$ & $\begin{array}{l}\text { Cirrhosis of liver, } \\
\text { sepsis }\end{array}$ & 3 & 227 & 2 & PB840 & $\mathrm{PC}$ & 7.7-9.9 & 282 & 22 & 29 & 0 \\
\hline 2 & 78 & M & $\begin{array}{l}\text { Pneumonia, old } \\
\text { cerebrovascular } \\
\text { accident }\end{array}$ & 2 & 400 & 7 & PB840 & $\begin{array}{l}\mathrm{PC} \\
\mathrm{VC}\end{array}$ & $\begin{array}{l}8.4 \\
7.1\end{array}$ & 313 & $\begin{array}{l}6 \\
3\end{array}$ & $\begin{array}{r}14 \\
0\end{array}$ & $\begin{array}{r}16 \\
8\end{array}$ \\
\hline 3 & 78 & $\mathrm{M}$ & $\begin{array}{l}\text { COPD, lung } \\
\text { cancer }\end{array}$ & 5 & 196 & 7 & Galileo & $\mathrm{PC}$ & 6.8 & 413 & 0 & 22 & 0 \\
\hline 4 & 80 & $\mathrm{~F}$ & VAP & 5 & 288 & 30 & Galileo & $\begin{array}{l}\mathrm{VC} \\
\mathrm{PC}\end{array}$ & $\begin{array}{l}8.3 \\
9.9\end{array}$ & 175 & $\begin{array}{l}0 \\
0\end{array}$ & $\begin{array}{l}11 \\
52\end{array}$ & $\begin{array}{r}0 \\
16\end{array}$ \\
\hline 5 & 55 & M & $\begin{array}{l}\text { COPD, } \\
\text { pneumothorax }\end{array}$ & 2 & 443 & 16 & Galileo & $\begin{array}{l}\text { VC } \\
\text { PC }\end{array}$ & $\begin{array}{l}7.4 \\
9.9\end{array}$ & 278 & $\begin{array}{l}42 \\
14\end{array}$ & $\begin{array}{r}31 \\
2\end{array}$ & $\begin{array}{l}0 \\
0\end{array}$ \\
\hline 6 & 43 & $\mathrm{~F}$ & $\begin{array}{l}\text { Systemic lupus } \\
\text { erythematosus, } \\
\text { pneumonia }\end{array}$ & 5 & 135 & 18 & PB840 & $\begin{array}{l}\mathrm{VC} \\
\mathrm{PC}\end{array}$ & $\begin{array}{l}6.4 \\
7.3\end{array}$ & 344 & $\begin{array}{l}3 \\
1\end{array}$ & $\begin{array}{r}3 \\
17\end{array}$ & $\begin{array}{l}0 \\
0\end{array}$ \\
\hline 7 & 88 & M & $\begin{array}{l}\text { Pneumonia, } \\
\text { ARDS }\end{array}$ & 5 & 139 & 4 & Servo-i & PS & 7.4 & 391 & 5 & 0 & 0 \\
\hline 8 & 89 & $\mathrm{M}$ & $\begin{array}{l}\text { Old } \\
\text { cerebrovascular } \\
\text { accident, } \\
\text { pneumonia }\end{array}$ & 4 & 486 & 3 & PB840 & $\begin{array}{l}\text { VC } \\
\text { PS }\end{array}$ & $\begin{array}{c}7.8 \\
9.2-10.4\end{array}$ & 261 & $\begin{array}{l}0 \\
0\end{array}$ & $\begin{array}{r}10 \\
0\end{array}$ & $\begin{array}{l}1 \\
8\end{array}$ \\
\hline 9 & 72 & $\mathrm{~F}$ & $\begin{array}{l}\text { Bacteremia, } \\
\text { septic emboli }\end{array}$ & Coma & 379 & 6 & PB840 & $\mathrm{VC}$ & 11.3 & 266 & 1 & 8 & 0 \\
\hline 10 & 50 & M & $\begin{array}{c}\text { Liver cirrhosis, } \\
\text { septic shock }\end{array}$ & Coma & 214 & 13 & Galileo & $\begin{array}{l}\text { VC } \\
\text { PS }\end{array}$ & $\begin{array}{r}8.2 \\
10.9\end{array}$ & 495 & $\begin{array}{r}20 \\
0\end{array}$ & $\begin{array}{l}3 \\
0\end{array}$ & $\begin{array}{l}0 \\
1\end{array}$ \\
\hline 11 & 62 & $\mathrm{~F}$ & $\begin{array}{l}\text { Congestive heart } \\
\text { failure, lung } \\
\text { edema }\end{array}$ & Coma & 300 & 7 & PB840 & $\begin{array}{l}\mathrm{PC} \\
\mathrm{VC}\end{array}$ & $\begin{array}{c}6.0-9.7 \\
8.0\end{array}$ & 252 & $\begin{array}{r}23 \\
5\end{array}$ & $\begin{array}{l}2 \\
1\end{array}$ & $\begin{array}{l}0 \\
0\end{array}$ \\
\hline 12 & 82 & $\mathrm{M}$ & Pneumonia & 3 & 305 & 8 & PB840 & $\mathrm{VC}$ & 6.6 & 383 & 1 & 36 & 0 \\
\hline 13 & 89 & $\mathrm{~F}$ & $\begin{array}{l}\text { Pneumonia, old } \\
\text { cerebrovascular } \\
\text { accident }\end{array}$ & 5 & 373 & 4 & PB840 & PS & 5.4 & 298 & 20 & 0 & 0 \\
\hline 14 & 70 & M & $\begin{array}{l}\text { COPD, } \\
\text { bronchiectasis }\end{array}$ & 5 & 263 & 3 & Servo-i & $\mathrm{VC}$ & 10.9 & 209 & 20 & 30 & 0 \\
\hline $\begin{array}{l}\text { M Mean } \pm \\
\mathrm{V}_{\mathrm{T}}=\text { tidal } \\
\mathrm{IBW}=\text { id } \\
\text { DT-P }=\mathrm{d} \\
\text { DT-V }=\mathrm{d} \\
\text { DT-A }=\mathrm{d} \\
\text { PC }=\text { pres } \\
\mathrm{VC}=\text { vol } \\
\text { VAP }=\text { ve } \\
\text { ARDS }= \\
\text { PS }=\text { pres }\end{array}$ & $\begin{array}{l}\text { volume } \\
\text { al body } \\
\text { uble trig } \\
\text { vuble trig } \\
\text { vuble trig } \\
\text { ure cont } \\
\text { me contr } \\
\text { tilator-a } \\
\text { cute resp } \\
\text { ure supp }\end{array}$ & $\begin{array}{l}\text { veight } \\
\text { gering } \\
\text { gering } \\
\text { gering } \\
\text { ol cont } \\
\text { ol cont } \\
\text { sociate } \\
\text { iratory } \\
\text { itt }\end{array}$ & $\begin{array}{l}5.2 \text { y. Mean } \pm \mathrm{SD}_{\mathrm{aO}} / \mathrm{F}_{\mathrm{II}} \\
\text { ith first breath patient-trigg } \\
\text { vith first breath ventilator-ts } \\
\text { vith first breath auto-trigger } \\
\text { nuous mandatory ventilatio } \\
\text { nuous mandatory ventilatior } \\
\text { pneumonia } \\
\text { listress syndrome }\end{array}$ & $\begin{array}{l}\mathrm{O}_{2} 296 \pm 1 \\
\text { ered } \\
\text { iggered } \\
\text { ed } \\
\text { n }\end{array}$ & $\mathrm{Hg} . \mathrm{Me}$ & SD days of & tion at tim & measurement & $=7.7 \mathrm{~d}$. & & & & \\
\hline
\end{tabular}

or flow changes in the trigger-delay phase in mechanically ventilated patients under flow-triggering, in which the airway-pressure drop may be extremely low. Pressure-drop change was more powerful than flow change for distinguishing DT-P from DT-V and DT-A. This information could be of value for objective classification of various forms of DT.

Some limitations to our study need to be addressed before further discussion. The first is the criterion we used for inspiratory effort: an esophageal pressure drop of
$>1 \mathrm{~cm} \mathrm{H}_{2} \mathrm{O}$ was taken as the objective criterion of inspiratory effort. ${ }^{8}$ As esophageal pressure is an indirect estimate of neural drive, the onset of neural inspiratory time may be different if transdiaphragmatic pressure or diaphragm electromyogram signal is used. However, the use of esophageal pressure as the indicated onset of neural inspiration should be acceptable, as the bias errors are the lowest, according to a recent study. ${ }^{13}$ Therefore, we are confident that our classification of various forms of DT should be accurate. 
Table 2. Airway Pressure and Flow Changes in the Trigger-Delay Phase of Double-Triggered Breaths

\begin{tabular}{lccr}
\hline \hline & $\begin{array}{c}\text { No. of } \\
\text { Breaths }\end{array}$ & $\begin{array}{c}\mathrm{PD}_{0.13} \\
\left(\mathrm{~cm} \mathrm{H}_{2} \mathrm{O}\right)\end{array}$ & \multicolumn{1}{c}{$\begin{array}{c}\mathrm{F}_{0.13} \\
(\mathrm{~L} / \mathrm{min})\end{array}$} \\
\hline DT-V & 271 & $0.16 \pm 0.12$ & $2.11 \pm 2.31$ \\
DT-A & 50 & $0.25 \pm 0.17$ & $2.64 \pm 2.07$ \\
DT-P & 186 & $1.34 \pm 0.67$ & $16.51 \pm 8.02$ \\
DT-P (PB840) & 85 & $1.03 \pm 0.40$ & $15.94 \pm 6.50$ \\
DT-P (Galileo) & 76 & $1.67 \pm 0.71$ & $19.83 \pm 7.03$ \\
DT-P (Servo-i) & 25 & $1.41 \pm 0.83$ & $8.35 \pm 9.40$
\end{tabular}

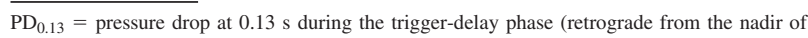
airway pressure tracing)

$\mathrm{F}_{0.13}=$ flow change at $0.13 \mathrm{~s}$ during the trigger delay phase (retrograde from the nadir of airway pressure tracing)

DT-V = Breaths for which the first breath of a double-triggered (DT) breath occurred at the ventilator set time trigger without concomitant esophageal pressure drop

DT-A = Breaths for which the first breath of DT occurred earlier than the ventilator set time trigger without concomitant esophageal pressure drop

DT-P $=$ Breaths for which the first breath of DT was associated with a drop of $>1 \mathrm{~cm} \mathrm{H}_{2} \mathrm{O}$ in esophageal pressure

DT-P $($ PB840) $=$ DT-P in patients on a PB840 ventilator

DT-P $($ Galileo $)=$ DT-P in patients on a Galileo ventilato

DT-P $($ Servo-i $)=$ DT-P in patients on a Servo-i ventilator

The second limitation is the small number of patients monitored and the variations in distributions of DT-P, DT-A, and DT-V in individual cases. In addition, only patients with esophageal pressure monitoring were included, and more than one type of ventilator was used. Although the trigger delays are not the same for different ventilators ${ }^{10}$ and the trigger delay was apparently affected by patients' effort and respiratory mechanics, airway pressure drop and flow change in the trigger-delay phase were apparently higher in the DT-P breaths with all 3 ventilator types. The optimal discriminating criteria for separating DT-P from DT-V and DT-A were similar when $\mathrm{P}_{0.13}$ was used. Therefore, our selected criteria for distinguishing the various forms of DT should be applicable to most patients, with modern ventilators.

In our study, $\mathrm{P}_{0.13}$ was much higher in DT-P than in DT-V or DT-A, and DT-P was usually associated with greater and longer inspiratory efforts, compared to non-DT breaths in the same patient. This finding implicated greater inspiratory drive when DT-P occurred. Although flow-triggering may be associated with minimal pressure deflection in the trigger-delay phase, a recent bench study that used the most sensitive trigger thresholds found that inspiratory trigger pressure (an analog to our pressure drop) averaged $2.2 \mathrm{~cm} \mathrm{H}_{2} \mathrm{O}$ in modern ventilators. ${ }^{10}$ Therefore, it is not surprising that the first DT-P breath was associated with a significantly higher pressure drop in the inspiratory trigger-delay phase, in comparison to those with DT-V or DT-A.

In addition to pressure drop, flow change in the preinspiratory phase was also much higher in DT-P breaths, and could also be used to separate DT-P from DT-V and DT-A. As DT-P is associated with a greater inspiratory effort that usually starts well before the end of expiration, it unsurprisingly leads to an increased flow change in a flow-triggered mode. In contrast, DT-V and DT-A are not associated with inspiratory effort, which are destined for smaller flow changes.

There are some clinical implications from our findings. DT-P is the second most frequent cause of patient-ventilator asynchrony, and identification of DT-P based on ambiguous airway pressure and flow change preceding the first assisted breath is subject to conflict. ${ }^{5}$ However, DT-P can be distinguished from DT-A and DT-V in the majority of cases, according to our pre-selected criteria. In our opinion, a fixed timing for calculating the pre-inspiratory pressure drop is needed for correct classification of DT. Once DTs are correctly classified, their management plans differ, as their underlying pathophysiologies are different. DT-P is associated with short inspiratory duration, which is a more frequent event when the pressurization ramp is rapid in pressure support ventilation. Directly prolonging the inspiratory time or manipulating the expiratory flow cycle threshold or pressurization time may abolish DT-P. In contrast, DT-V is associated with a faster mandatory respiratory rate, and reducing the mandatory rate or changing to a spontaneous breathing mode will synchronize the

Table 3. Optimal $\mathrm{PD}_{0.13}$ and $\mathrm{F}_{0.13}$ for Distinguishing DT-P, DT-V, and DT-A

\begin{tabular}{|c|c|c|c|c|c|c|}
\hline & $\begin{array}{l}\text { Optimal PD } 0.13 \\
\quad\left(\mathrm{~cm} \mathrm{H}_{2} \mathrm{O}\right)\end{array}$ & $\begin{array}{l}\text { Sensitivity } \\
(\%)\end{array}$ & $\begin{array}{l}\text { Specificity } \\
(\%)\end{array}$ & $\begin{array}{c}\text { Optimal F F } \\
\text { (L/min) }\end{array}$ & $\begin{array}{c}\text { Sensitivity } \\
(\%)\end{array}$ & $\begin{array}{c}\text { Specificity } \\
(\%)\end{array}$ \\
\hline All DT (507 breaths) & $\geq 0.49$ & 98 & 97 & $\geq 6.12$ & 91 & 94 \\
\hline PB840 (260 breaths with DT) & $\geq 0.48$ & 96 & 97 & $\geq 5.80$ & 100 & 94 \\
\hline Galileo (192 breaths with DT) & $\geq 0.54$ & 100 & 97 & $\geq 6.10$ & 100 & 97 \\
\hline Servo-i ( 55 breaths with DT) & $\geq 0.53$ & 100 & 100 & $\geq 1.82$ & 88 & 47 \\
\hline
\end{tabular}

$\mathrm{PD}_{0.13}=$ pressure drop at $0.13 \mathrm{~s}$ during the trigger-delay phase (retrograde from the nadir of airway pressure tracing)

$\mathrm{F}_{0.13}=$ flow change at $0.13 \mathrm{~s}$ during the trigger delay phase (retrograde from the nadir of airway pressure tracing)

DT-P $=$ double triggering with first breath patient-triggered

$\mathrm{DT}-\mathrm{V}=$ double triggering with first breath ventilator-triggered

DT-A $=$ double triggering with first breath auto-triggered 


\section{Classifying Different Types of Double Triggering}

ventilator with the patient's breathing. Successful management of our 12 patients with DT-P or DT-V confirmed this principle of ventilator adjustment.

\section{Conclusions}

DT-P can be easily differentiated from DT-V and DT-A with the pre-inspiratory pressure or flow change at $0.13 \mathrm{~s}$. Based on our recommended criteria, DT-P can be distinguished from DT-V and DT-A in the majority of cases. The high discriminatory power of our defined criteria may allow objective identification of DT when only airway pressure or flow is used.

\section{REFERENCES}

1. Thille AW, Rodriguez P, Cabello P, Lellouche F, Brochard L. Patient-ventilator asynchrony during assisted mechanical ventilation. Intensive Care Med 2006;2(10):1515-1522.

2. Nilsestuen JO, Hargett KD. Using ventilator graphics to identify patient-ventilator asynchrony. Respir Care 2005;50(2):202-232.

3. Brochard L, Lellouche F. Pressure support ventilation. In: Tobin MJ editor. Principles and practice of mechanical ventilation, 2nd edition. New York: McGraw-Hill; 2006:232.

4. Jubran A. Inspiratory flow rate: more may not be better. Crit Care Med 1999;27(4):670-671.
5. Chen $\mathrm{CW}$, Lin WC, Hsu CH. Pseudo-double-triggering. Intensive Care Med 2007;33(4):742-743.

6. Fanfulla F. Delmastro M, Berardinelli A, Lupo ND, Nava S. Effects of different ventilator settings on sleep and inspiratory effort in patients with neuromuscular disease. Am J Respir Crit Care Med 2005;172(5): 619-624.

7. Baydur A, Behrakis PK, Zin WA, Jaeger M, Millic-Emili J. A simple method of assessing the validity of the esophageal balloon technique. Am Rev Respir Dis 1982;126(5):788-791.

8. Leung P, Jubran A, Tobin MJ. Comparison of assisted ventilator modes on triggering, patient effort, and dyspnea. Am J Respir Crit Care Med 1997;155(6):1940-1948.

9. Takeuchi M, Williams P, Hess D, Kacmarek RM. Continuous positive airway pressure in new-generation mechanical ventilators: a lung model study. Anesthesiology 2002;96(1):162-172.

10. Thille AW, Lyazidi A, Richard JC, Galia F, Brochard L. A bench study of intensive-care-unit ventilators: new versus old and turbinebased versus compressed gas-based ventilators. Intensive Care Med 2009;35(8):1368-1376.

11. Marchese AD, Chipman D, de la Oliva P, Kacmarek RM. Adult ICU ventilators to provide neonatal ventilation: a lung simulator study. Intensive Care Med 2009;35(4):631-638.

12. Schisterman EF, Perkins NJ, Liu A, Bondell H. Optimal cut-point and its corresponding Youden index to discriminate individuals using pooled blood samples. Epidemiology 2005;16(1):73-81.

13. Parthasarathy S, Jubran A, Tobin MJ. Assessment of neural inspiratory time in ventilator-supported patients. Am J Respir Crit Care Med 2000;162(2 Pt 1):546-552. 